\title{
Leaching from new generation treated wood: a chemical approach
}

\author{
M. O. Lupsea ${ }^{1,2}$, H. Mathies ${ }^{3}$, U. Schoknecht $^{3}$, L. Tiruta-Barna ${ }^{1}$ \\ $\&$ N. Schiopu ${ }^{2}$ \\ ${ }^{1}$ Université de Toulouse; INSA, UPS, INP, LISBP, CNRS, France \\ ${ }^{2}$ Université Paris-Est, Centre Scientifique et Technique du Bâtiment, \\ France \\ ${ }^{3} B A M$ - Bundesanstalt für Materialforschung und - prüfung, Germany
}

\begin{abstract}
Leaching of biocides from construction products is currently a research topic receiving attention from the European regulation authorities (CEN/TC 351). In this paper we have focused on the leaching behaviour of CBA (copper-borateazoles) treated Pinus sylvestris. To better define the chemistry of the leaching phenomena, two leaching tests (a static equilibrium test and a dynamic surface leaching test) have been carried out on untreated and treated wood, which offered more information about how the leaching of biocides interferes with other substances released from the wood structure. Eluates, in liquid and lyophilised form, were further analyzed by analytical methods. Organic (tebuconazole) and inorganic ( $\mathrm{Cu}, \mathrm{B})$ biocides were quantified and several organic compounds have been identified (e.g. carboxylic acids, phenols, amines, etc.). Also, the total amount of phenols and of carboxylic groups was determined. Results on inorganic compounds are in accordance with previous studies made on treated wood. Furthermore, organic carbon, tebuconazole and other organic compounds' behaviour was extensively investigated. This study aims to complete existing leaching data and to help developing a chemical model for several biocides in wood, including $\mathrm{Cu}, \mathrm{B}$ and tebuconazole.

Keywords: leaching, CBA treated wood, biocide, organic compounds.
\end{abstract}




\section{Introduction}

Leaching of biocides from construction products is currently a research topic receiving attention from the European regulation authorities (CEN/TC 351). In this paper we focus on leaching of biocides from treated wood. Being an economical, durable and aesthetically pleasing building material, treated wood is a frequent choice for construction projects. However, we need to ensure that biocides used for the treatment of wood against biological attack, do not represent a threat to people or environment. Previous studies generally report high leaching rates from treated wood exposed in natural conditions or in laboratory tests, depending on the type of preservative [1-3].

During the years, different classes of biocides have been used in wood treatment, due to legislative constraints imposing increasingly strict conditions. Nowadays, the alternatives to prohibited biocides (e.g. CCA - CopperChromium-Arsenate) are the so called "new generation" biocides, based, for example, on boron, copper and various organic substances of synthesis such as propiconazole or tebuconazole. The product studied in this research consists of Pinus sylvestris treated with copper-boron-tebuconazole (further called "CBA").

Leaching from wood has been extensively investigated for the case of inorganic preservatives, especially CCA [4]. Factors that affect leaching of wood preservatives have already been summarized by several authors [4-5].

In order to build a leaching model that estimates organic and inorganic biocidal emissions from treated wood, hypotheses on bindings between preservatives and wood structure have to be made. The questions to be answered are:

- How do $\mathrm{Cu}, \mathrm{B}$ and tebuconazole bind on the wood structure?

- Which is the leaching mechanism from treated wood, for metals and tebuconazole?

- How does the leaching of biocides interfere with other substances released from the wood structure?

An extensive literature exists and provides knowledge about the binding mechanisms of different biocides [6-8]. However, the quantitative description of leaching mechanisms still remains a research objective. In [9], a quantitative model was proposed for describing the leaching of metal biocides from treated wood by taking into account binding mechanisms in wood and extractives' release and highlighting the extractives' influence on metals' mobilisation. Nevertheless, with few exceptions, the release and the interactions of organic compounds of wood have been disregarded until now.

The objective of this work is to better understand the leaching behaviour of treated wood, notably the organic compounds' release (including the organic biocide), the changes induced by the treatment process, and the behaviour of all biocide compounds, in order to help developing a chemical model for biocides in wood, and further a more complex coupled chemical-transport model. 
The methodology adopted is based on experimental leaching tests performed under different conditions. Two standard leaching tests were applied on CBA treated and untreated wood samples:

1. ANC test (Acid/base Neutralisation Capacity test) based on XP CEN/TS 14429 [10], aims to describe $\mathrm{pH}$ dependency of leaching for different components (i.e. active substances, ions, etc.). It provides information on the influence of $\mathrm{pH}$ on pollutant release, acid/base neutralisation capacity and physico-chemical stability of the material.

2. DSLT (Dynamic Surface Leaching Test) carried out cf. OECD 313 [11], is used to describe time dependency of leaching for different components. Punctual emission rates are calculated from analytical results.

Different qualitative and quantitative analytical methods were employed for characterising the obtained leachates.

\section{Materials and methods}

\subsection{Wood samples}

Two types of Pinus sylvestris samples were used: wood that was cut off 9 years ago (later called "conditioned") and Pinus sylvestris shavings collected from different trees in a carpentry (later called "fresh"). A description of the samples and tests performed is given in table 1 .

Table 1: Pinus sylvestris samples and the corresponding performed leaching tests.

\begin{tabular}{|c|c|c|c|c|c|}
\hline \multirow[b]{2}{*}{$\begin{array}{l}\text { Sample } \\
\text { code }\end{array}$} & \multirow[b]{2}{*}{ Description } & \multirow[b]{2}{*}{ Size } & \multirow{2}{*}{$\begin{array}{c}\text { Treatment } \\
\text { with wood } \\
\text { preservative }^{(1)}\end{array}$} & \multicolumn{2}{|c|}{ Tests performed } \\
\hline & & & & ANC & $\begin{array}{c}\text { DSLT } \\
(\text { OECD 313) }\end{array}$ \\
\hline $\mathbf{U F}$ & $\begin{array}{l}\text { up to } 1 \text { year old } \\
\text { shavings }^{(2)}\end{array}$ & crushed $\leq 1 \mathrm{~mm}$ & without & $\mathrm{x}$ & \\
\hline \multirow{2}{*}{ UA } & \multirow{2}{*}{$\begin{array}{l}\text { cut off } 9 \text { years } \\
\text { ago }^{(3)}\end{array}$} & crushed $\leq 1 \mathrm{~mm}$ & without & $\mathrm{x}$ & \\
\hline & & monolithic & without & & $\mathrm{x}$ \\
\hline $\mathbf{B F}$ & $\begin{array}{l}\text { up to } 1 \text { year old } \\
\text { shavings }^{(2)}\end{array}$ & crushed $\leq 1 \mathrm{~mm}$ & $16 \mathrm{~kg} / \mathrm{m}^{3}$ & $\mathrm{x}$ & \\
\hline \multirow{2}{*}{$\mathbf{B A}$} & \multirow{2}{*}{$\begin{array}{c}\text { cut off } 9 \text { years } \\
\text { ago }^{(3)}\end{array}$} & crushed $\leq 1 \mathrm{~mm}$ & $16 \mathrm{~kg} / \mathrm{m}^{3}$ & $\mathrm{x}$ & \\
\hline & & monolithic & $16 \mathrm{~kg} / \mathrm{m}^{3}$ & & $\mathrm{x}$ \\
\hline
\end{tabular}

${ }^{(1)}$ Copper boron azole preservative CBA.

${ }^{(2)}$ Shavings from Pinus sylvestris collected in BAM carpentry.

${ }^{(3)}$ Trees (Pinus sylvestris) were cut off 9 years ago and conditioned at $20 \pm 2{ }^{\circ} \mathrm{C}$ and $65 \pm 5 \%$ relative humidity (cf. EN 113).

Wood samples ("conditioned" and "fresh") were treated by vacuum pressure impregnation with an aqueous solution $(2.1 \%)$ of a commercial preservative (as described in the EN 113 standard). The commercial wood preservative consisted 
of copper carbonate $(22.5 \%)$ boric acid $(4.9 \%)$, tebuconazole $(0.53 \%)$. In addition, the preservative contained amines, mainly monoethanolamine (MEA) and 2-ethylhexanoic acid.

Monolithic test specimens $\left(1.5 * 2.5 * 5 \mathrm{~cm}^{3}\right)$ have been treated by vacuum pressure impregnation with a $2.1 \%$ solution of the concentrated preservative in water (as described in EN 113 standard [12]). The final concentration was $16 \mathrm{~kg}$ CBA per $\mathrm{m}^{3}$ of wood, i.e. $2 \mathrm{~kg} / \mathrm{m}^{3}$ copper, $0.1 \mathrm{~kg} / \mathrm{m}^{3}$ boron and $0.085 \mathrm{~kg} / \mathrm{m}^{3}$ tebuconazole. BF samples were obtained by treating UF shavings with a $2.1 \%$ solution of CBA in a mixture of acetone and water $\left(16 \mathrm{~kg} / \mathrm{m}^{3} \mathrm{CBA}\right)$. The shavings dried within two weeks at room temperature and pressure, until they reached a constant mass.

\subsection{Leaching tests}

The ANC test was carried out based on the XP CEN/TS 14429 standard. This test aims to describe $\mathrm{pH}$ dependency of leaching for different components. It provides information on the influence of $\mathrm{pH}$ on pollutant release, acid/base neutralisation capacity and physico-chemical stability of the material. UA and BA samples crushed at $\leq 1 \mathrm{~mm}$ were stirred with demineralised water (liquid to solid ratio of $10 \mathrm{~mL} / \mathrm{g}$ ) for 48 hours. Here, we replaced $\mathrm{HNO}_{3}$ solutions (as advised in the standard for inorganic compounds) by $\mathrm{HCl}$ solutions, because of the strong oxidation character of $\mathrm{HNO}_{3}$. Filtered eluates have been analyzed in order to identify or quantify cations, anions and organic substances.

DSLT test was carried out according to the OECD 313 standard. Sets of 5 test specimens were investigated in triplicate for treated wood (BA) and for one control with untreated wood ("blank", UA), having the ratio wood surface to leachate $0.4 \mathrm{~cm}^{2} / \mathrm{mL}$. They were end-sealed with 2 coatings of a varnish in order to observe leaching by transversal surfaces mainly. This is justified by the fact that leaching from transversal surfaces is slower than from longitudinal surfaces due to the anisotropy of wood [4]. Eluates were collected over the exposure period $(0.25,1,2,4,8,15,22,29$ days) and chemically analyzed. Punctual and cumulative emission rates have been calculated from analytical results.

\subsection{Analytical method}

Substances of interest were chosen in accordance with previous studies [9] and after an inorganic and organic screening on eluates. Total Organic Carbon (TOC) and mineral species $\left(\mathrm{K}^{+}, \mathrm{Ca}^{+2}, \mathrm{Cu}^{+2}, \mathrm{Zn}^{+2}, \mathrm{BO}_{3}^{-}, \mathrm{Cl}^{-}, \mathrm{NO}_{2}^{-}, \mathrm{Br}^{-}, \mathrm{NO}_{3}^{-}, \mathrm{PO}_{4}{ }^{3-}\right.$, $\mathrm{SO}_{4}{ }^{2}, \mathrm{CrO}_{4}{ }^{-2}$ ) have been selected in order to better understand the chemical context. Tebuconazole, organic acids (individual and total carboxylic groups) and total phenols were analyzed as described below.

In order to better identify the substances released from CBA treated wood, we divided the eluates from ANC and DSLT tests in two parts: (1) eluates in native liquid and (2) eluates to be lyophilised for identification of soluble organic compounds from wood. A global overview of the analytical methods used on eluates from both leaching tests is presented in figure 1 . 


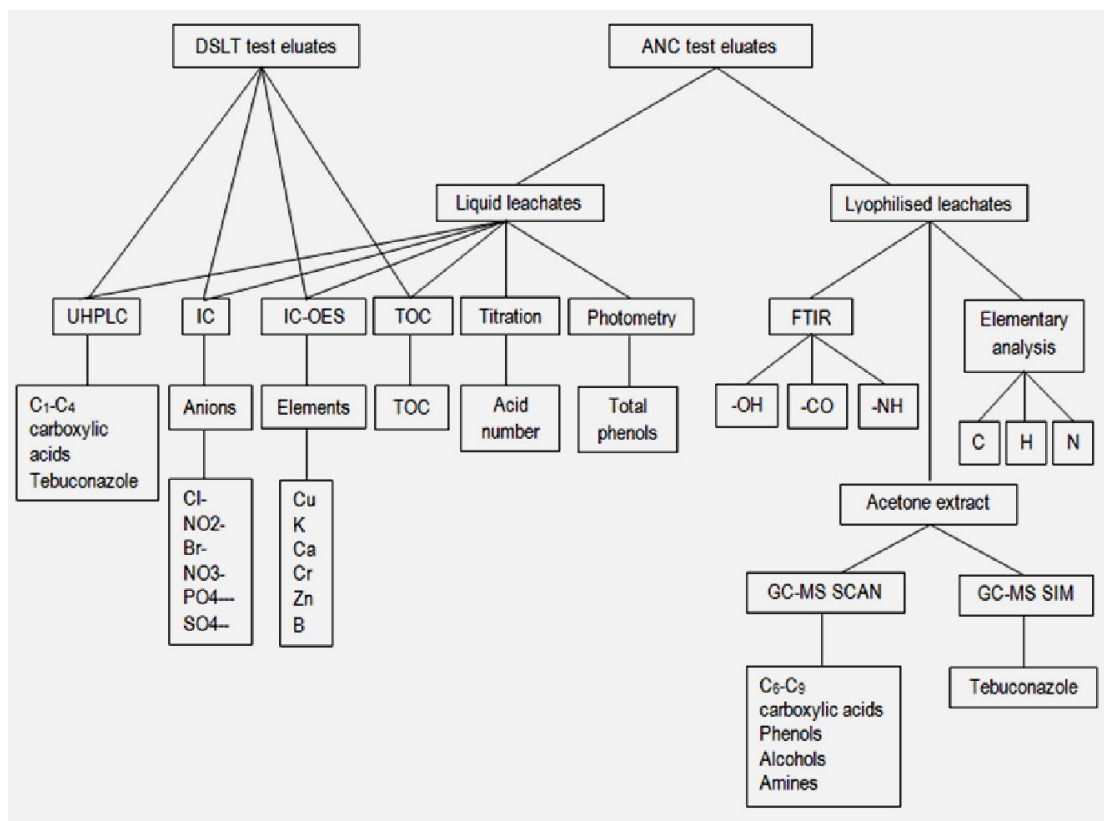

Figure 1: Analytical methods schema.

\subsubsection{Analysis of liquid eluates}

TOC was measured cf. DIN EN ISO 1484 standard, elemental analysis was performed by ICP-OES (Optical Emission Spectrometry) cf. DIN EN ISO 11885 standard and anions were quantified by IC (Ion Chromatography) cf. DIN EN ISO 10304-4 standard. Tebuconazole was quantified by GC-MS (Gas Chromatography - Mass Spectrometry) and C6-C9 acids, alcohols, terpenes, amines and other compounds have been identified by GC-MS screening methods. Besides these carboxylic acids, formic, acetic, maleic and citric acids have been identified and quantified in leachates by UHPLC (UltraHigh Pressure Liquid Chromatography).

Total concentration of carboxylic groups was measured by titration. For total phenols' quantification we used the photometric method called Modified Prussian Blue Assay for Total Phenols [13].

\subsubsection{Analysis of lyophilised eluates}

After filtration, ANC eluates with alkaline $\mathrm{pH}$ have been first neutralised with a $0.1 \mathrm{M} \mathrm{HCl}$ solution, in view of the deprotonation of carboxylic and phenolic groups, and then, by lyophilisation, brought to solid form. For the identification of functional organic groups (-CO, $-\mathrm{OH},-\mathrm{NO}$, etc.), the organic solid matter thus obtained was extracted by acetone and analyzed by GS-MS methods. An elemental analysis for carbon, nitrogen and hydrogen was also performed using a Macro-Elementary Analyzer. The limits of quantification for the quantitative determinations are presented in table 2 . 
Table 2: $\quad$ Limits of quantification for quantitative determinations.

\begin{tabular}{|c|c|c|c|}
\hline Substance & Analytical method & Unit & $\begin{array}{c}\text { Limit of } \\
\text { quantification }\end{array}$ \\
\hline TOC & TOC analysis & $\overline{\mathrm{mg} / \mathrm{L}}$ & 0.05 \\
\hline $\mathrm{Cl}^{-}$ & \multirow{6}{*}{ 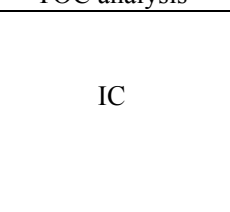 } & $\mathrm{mg} / \mathrm{L}$ & 0.4 \\
\hline $\mathrm{NO}_{2}^{-}$ & & $\mathrm{mg} / \mathrm{L}$ & 0.4 \\
\hline $\mathrm{Br}^{-}$ & & $\mathrm{mg} / \mathrm{L}$ & 0.3 \\
\hline $\mathrm{NO}_{3}{ }^{-}$ & & $\mathrm{mg} / \mathrm{L}$ & 1 \\
\hline $\mathrm{PO}_{4}{ }^{3-}$ & & $\mathrm{mg} / \mathrm{L}$ & 1 \\
\hline $\mathrm{SO}_{4}{ }^{2-}$ & & $\mathrm{mg} / \mathrm{L}$ & 2 \\
\hline $\mathrm{B}$ & \multirow{5}{*}{ ICP-OES } & $\mathrm{mg} / \mathrm{L}$ & 0.001 \\
\hline $\mathrm{Ca}$ & & $\mathrm{mg} / \mathrm{L}$ & 0.4 \\
\hline $\mathrm{Cu}$ & & $\mathrm{mg} / \mathrm{L}$ & 0.008 \\
\hline $\mathrm{K}$ & & $\mathrm{mg} / \mathrm{L}$ & 0.6 \\
\hline $\mathrm{Zn}$ & & $\mathrm{mg} / \mathrm{L}$ & 0.3 \\
\hline $\mathrm{C}$ & \multirow{3}{*}{$\begin{array}{l}\text { Macro-elementary } \\
\text { analysis }\end{array}$} & $\mu \mathrm{g}$ & 41.9 \\
\hline $\mathrm{N}$ & & $\mu \mathrm{g}$ & 10.2 \\
\hline $\mathrm{H}$ & & $\mu \mathrm{g}$ & 3.8 \\
\hline
\end{tabular}

\section{Results and discussions}

\subsection{Results from ANC test}

ANC tests delivered results under two forms: (i) final $\mathrm{pH}$ value of the eluate in function of $\mathrm{H}^{+}$moles added per L solution and (ii) variation of the concentration of target substances with $\mathrm{pH}$. Curves from ANC test are presented in figure 2 for some compounds. Graphs show that the natural $\mathrm{pH}$ for untreated wood lies between 4 and 5, while eluates from treated wood (without reactant for $\mathrm{pH}$ adjustment) are slightly alkaline, with a $\mathrm{pH}$ between 7 and 8 . This can be explained by the alkalinity of MEA introduced with the CBA treatment solution and trapped on the wood structure.

As expected, $\mathrm{Cu}, \mathrm{B}$ and tebuconazole have been found only in eluates on treated wood. While the concentration of $\mathrm{Cu}$ in eluates from "conditioned" and "fresh" samples follow similar curves, in the case of B one can observe a slightly higher concentration in the eluates on treated "conditioned" wood. B concentration is almost constant in the $\mathrm{pH}$ range (around $30 \%$ of the initial content). $\mathrm{Cu}$ showed a variation in the concentration of one order of magnitude over the $\mathrm{pH}$ range with a minimum at neutral $\mathrm{pH}$ (around $25 \%$ of the initial content). This proves that $\mathrm{Cu}$ is linked to active centres of the wood structure (carboxylic and phenolic groups), which makes it less leachable. However, with $\mathrm{pH}$ decrease, $\mathrm{Cu}$ leaches more, due to site protonation. Tebuconazole concentration in leachates shows an increase with $\mathrm{pH}$. It leaches up to $17 \%$ from its initial total content in the sample and 10 times less than its solubility (0.32 mg/L [14]).

Carboxylic acids like formic, acetic and maleic acids are released from both treated and untreated samples (identified and quantified by UHPLC). Their concentration is of the same order of magnitude. These carboxylic acids are susceptible of leaching from the wood structure. 


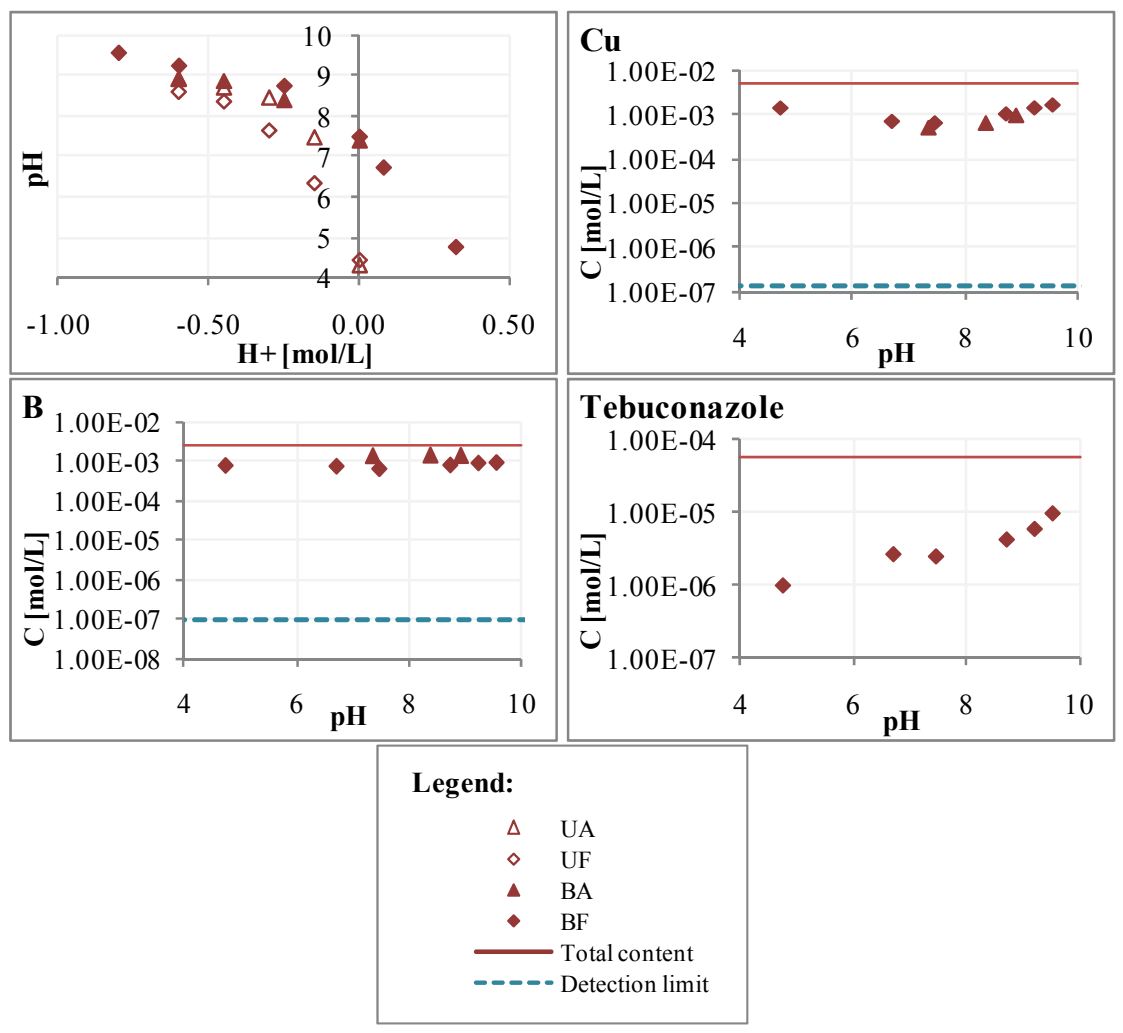

Figure 2: $\quad$ ANC results.

The titration of carboxylic groups showed that the concentration in eluates from treated wood is lower than for untreated wood. In eluates on treated wood, these acids could have been neutralised to esters, salts or chelants. Carboxylic acids and phenols have a similar behaviour, i.e. their concentration increases with $\mathrm{pH}$. This behaviour could be explained by hydrolysis processes induced by $\mathrm{OH}-$ on the wood polymers and liberation in solution of small molecules containing phenolic and carboxylic groups. Also, a difference between the concentration of both groups in eluates from untreated "fresh" and "conditioned" wood is observed, which could be due to the volatilisation in time (duration of conditioning) of different extractibles from wood. A volatilisation process could explain also the differences observed between acids' concentration form fresh treated wood and conditioned (9 year old) untreated sample.

Two global parameters for dissolved organic matter have been determined: TOC on liquid eluates and elemental $\mathrm{C}$ on lyophilised eluates. They exhibit similar behaviour with respect to $\mathrm{pH}$ and type of sample. TOC data obtained by eluate analysis (expressed as $\mathrm{mg}$ of $\mathrm{C}$ per L) was compared to data obtained from carbon elemental analysis (in $\mathrm{mg} \mathrm{C}$ per L) made on solid lyophilised eluates (see figure 3). The concentration of $\mathrm{TOC}$ in eluates is almost equal to the 
concentration of carbon from solid residues. The small differences could be explained by the volatilisation of some compounds (such as acetic acid) during the lyophilisation process. However, for both measurements, the concentration of organic carbon increases from acid to alkaline conditions.
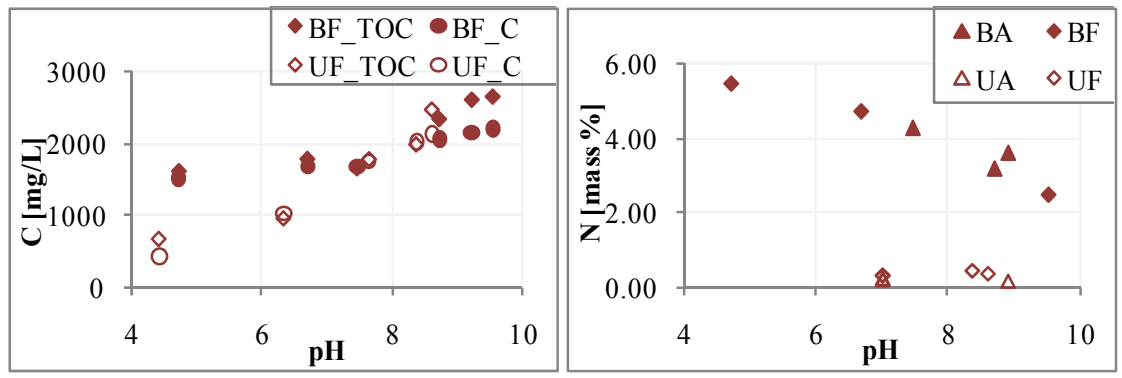

Figure 3: Total organic carbon released by treated and untreated samples, determined as: 1) TOC concentration in leachates and 2) $\mathrm{C}$ in solid residues form lyophilised leachates; $\mathrm{N}$ mass $\%$ in lyophilised eluates on treated and untreated wood, from ANC tests.

The organic matter analyzed by the global parameters TOC or C is in reality of a very complex composition as proved by GC-MS chromatograms obtained on lyophilized leachates. The composition of leachates from treated and untreated wood is very different: emissions from untreated wood contain mainly organic acids (hexanoic acid, heptanoic acid, octanoic acid, nonanoic acid), alcohols, phenols and ketones, while eluates from treated wood contain besides organic acids, the 2-ethyl hexanoic acid and MEA identified and other (unidentified) compounds containing oxygen and nitrogen.

Elementary analysis measured the mass \% of nitrogen in the lyophilised eluates (figure 3). One can notice that the $\%$ of nitrogen in eluates from treated wood is up to 25 times higher than for the untreated samples, and the release decreases with $\mathrm{pH}$ increase. This could be explained by the leaching of amines (e.g. MEA), which is contained in the treatment solution at about $1 \%$, or substances derived from MEA. Besides these many different substances containing nitrogen bounds have been identified on the screening chromatograms of eluates obtained from treated wood, but not for those obtained from untreated samples. One explanation could be the modification of MEA molecules by interaction with other endogenous organic molecules.

\subsection{DSLT results}

DSLT results are presented in curves of variation of concentration in time (see figure 4) for triplicate samples of treated wood (named sample $x, y$ and z) and one untreated sample (blank). The presentation of concentrations of the single eluates avoids the propagation of errors and permits to compare emissions from treated and untreated samples, and to evaluate the reproducibility of data. 


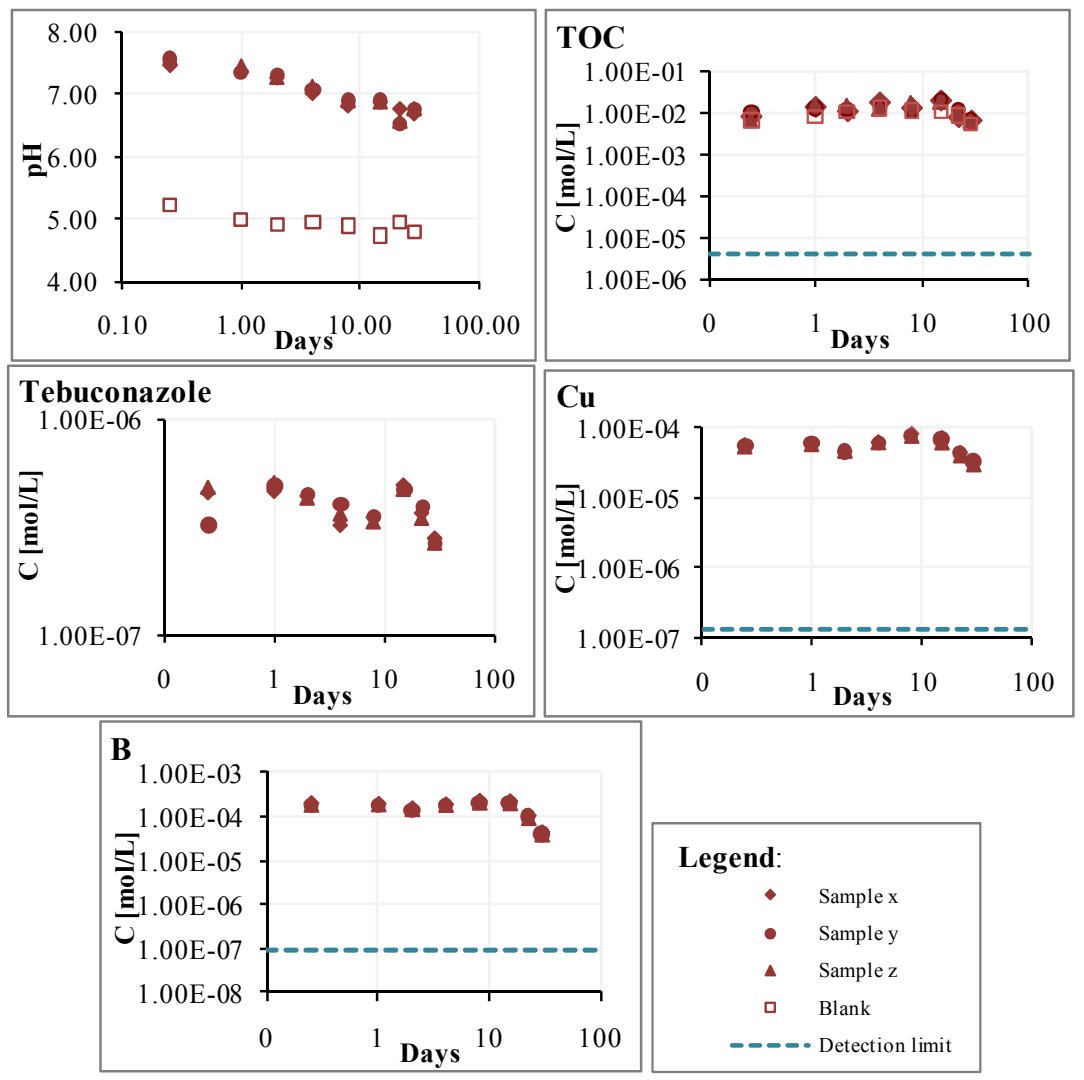

Figure 4: $\quad$ DSLT curves $\mathrm{C}=\mathrm{f}$ (time).

The observed concentrations are the result of chemical changes in contact with water and of the transport processes (e.g. diffusion) in the pores of wood samples. The objective of this test is to evaluate the coupled chemistry-transport processes. Also, the behaviour of treated and untreated wood is compared for the common species $(\mathrm{Cu}$, tebuconazole and $\mathrm{B}$ are released only from the treated samples).

TOC concentration is slightly smaller in eluates from untreated samples than those from treated wood samples. The same behaviour is observed in ANC test at neutral $\mathrm{pH}$. This could be explained by the addition of organic compounds into the wood with the preservative solution and also by the higher $\mathrm{pH}$ of treated samples that enables more organic compounds to be solubilised. Therefore, this behaviour is also observed for acetic acid.

\section{Leaching mechanism proposition}

Wood is a heterogeneous, hygroscopic, cellular and anisotropic material. It is composed of cells, and the cell walls are composed of micro-fibrils of cellulose, 
hemicelluloses, lignin, other minor polysaccharides and a small fraction of extractives [15]. Treatment of wood causes a series of reactions between wood components and constituents of the wood preservative, e.g. complexation, ion exchange, adsorption. The "chemistry" of treated wood depends on wood species, age of wood, formulation of the wood preservative, etc. Several authors have modelled metal release from treated wood, using simplifying hypotheses: wood properties and biocide fixation were not considered, or only diffusion and $1^{\text {st }}$ order reaction kinetics were regarded, without a description of the chemical properties and reactions [4,5]. A more complex modelling approach has been described in [9] taking into account complexation reactions for metals and hydrolysis of organic extractives. Nevertheless, the problem of missing data (lack of leaching data) was solved by several hypotheses for metal fixation and by adjustment of several parameters on experimental leaching test data.

Starting from experimental observations presented in the chapters above, we will further investigate those relations between constituents of wood and formulations that have main influence on the leaching process.

\subsection{Copper}

Previous studies made on CBA treated wood $[8,16]$ show that cupric ions react with MEA to form stable five-membered chelate rings in solution, by the amine action as a bidentate ligand via the $\mathrm{N}$ and $\mathrm{O}$ atoms $(\log \mathrm{K}=14.9$ [8]), depending on the nature of amine ligands. The bonding sites are weak acidic groups of wood components, e.g., carboxylic and phenolic hydroxyl groups, which dissociate according to the ambient $\mathrm{pH}[6]$.

\subsection{Tebuconazole}

Tebuconazole impregnation and binding with wood structure has been little investigated. Thus, some studies have been made on a possible metal-azole complex, i.e. Cu-tebuconazole complex [17]. Divalent copper complexes with metal:azole ratio 1:2 have been obtained at room temperature, with tebuconazole.

Although no precisely relevant literature data have been found, ethanolamine probably binds copper and other metals stronger than tebuconazole. In general, it seems more likely that wood treated with ethanolamine-based formulations may contain predominantly uncomplexed tebuconazole [17]. It can be considered that tebuconazole is fixed on wood by physical absorption and therefore only transport phenomena (e.g. diffusion) within treated wood and transfer from the wood surface to water is considered to influence the leaching of tebuconazole (no chemical reactions are considered).

\subsection{Boron}

Boron is introduced in wood as boric acid and forms organic complexes in which it is linked to wood by O bridges [18]. Its leachability from treated wood is recognised to be high, confirmed also by the ANC and DSLT tests carried out in this study. A reaction between the negatively charged hydroxocomplex $\mathrm{B}(\mathrm{OH})_{4}{ }^{-}$ 
and hydroxyl groups on polysaccharides with formation of a bidentate complex has been proposed [7]. This reaction requires the presence of two $-\mathrm{OH}$ in favourable position.

\section{Conclusions}

Leaching from CBA treated wood has been investigated, with emphasize on organic compounds behaviour. Several methods have been applied on eluates obtained from ANC and DSLT tests. Results on inorganic compounds are in accordance with previous studies made on treated wood [5, 9, 19]. TOC, tebuconazole and other organic compounds' behaviour was extensively investigated. The main conclusions obtained in this study can be summarized as below:

- Organic compounds are naturally released from wood, carboxylic functions have been mainly identified and quantified (e.g. acetic, formic and maleic acids), but other groupings like alcohol, phenol and ketone are also present.

- In the case of amine based CBA treated samples, nitrogen containing compounds are released in important quantities, especially at low $\mathrm{pH}$.

- Concerning copper behaviour, the experimental observations seem to validate earlier proposed mechanisms for copper, i.e. its fixation on wood structure via complexation reactions involving MEA as soluble species and carboxylic and phenolic groups on wood.

- Boron exhibits a high release level very close to its total content in the wood sample.

- Tebuconazole is released in lesser extent if compared with its initial content in the wood samples, its fixation on solid wood structure could be envisaged rather by hydrophobic interactions (physical adsorption)

This study aims to complete leaching data presented in previous studies [3-5, 9] in order to help developing the chemical model for biocides in wood. The chemical model is an essential step in the development of a coupled chemicaltransport model. The final goal is to reach equilibrium between the technical efficiency and the environmental impact of preservation treatment of wood. This could be done only by a fine comprehension of the leaching mechanisms, especially on typical in-service long-term leaching behaviour, for which additional research is needed.

\section{References}

[1] Lebow, S., Leaching of wood preservatives components and their mobility in the environment, Gen. Tech. Rep. WI: U.S. Department of Agriculture, Forest Service, Forest Products Laboratory, 1996.

[2] Ahn, S.H., Oh, S.C., Choi, I., Han, G., Jeong, H., Kim, K., Yoon, Y. and Yang, I., Environmentally friendly wood preservatives formulated with enzymatichydrolyzed okara, copper and/or boron salts, J. Hazard. Mater. 178, pp. 604-611, 2010. 
[3] van der Sloot, H.A. and van Zomeren, A., Mechanisms and controlling factors in the release of contaminants from treated wood, Leaching of Biocides from Facade Coatings, Rapperswil, 2011.

[4] Waldron, L. and Cooper, P.A., Modeling of simultaneous threedimensional leaching and chemical reaction of CCA components in unfixed wood exposed to water, Wood Sci Technol, 44, pp. 129-147, 2010.

[5] Schoknecht, U., Mathies, H., Morsing, N., Lindegaard, B., van der Sloot, H., van Zomeren, A., Deroubaix, G., Legay, S., Tadeo, J.L., GarcíaValcárcel, A.I., Gigliotti G., Zadra, C., Hajšlová, J., Tomaniová, M., Wegner, R., Bornkessel, C. and Fürhapper, C., Inter-laboratory Evaluation of Laboratory Test Methods to estimate the Leaching from Treated Wood, Agreement Number 04/375757/C4, 2005.

[6] Cooper, P.A., Cation exchange adsorption of copper on wood, Wood Protection, 1, pp. 9-14, 1991.

[7] Ramos, A.M., Caldeira Jorge, F. and Botelho, C., Boron fixation in wood: studies of fixation mechanisms using model compounds and maritime pine, Holz Roh Werkst, 64, pp. 445-450, 2006.

[8] Lee, M.J., Adsorption of alkaline copper quat components in wood mechanisms and influencing factors, PhD Thesis, Univ. Toronto, 2011.

[9] Tiruta-Barna, L. and Schiopu, N., Modelling inorganic biocide emission from treated wood in water, J. Hazard. Mater., 192, pp. 1476-1483, 2011.

[10] XP CEN/TS 14429, Characterization of waste, Leaching behaviour tests, Influence of $\mathrm{pH}$ on leaching with initial acid/base addition, Brussels, 2006.

[11] OECD 313 guideline proposal, Estimation of emissions from preservative treated wood to the environment: laboratory method for wooden commodities that are not covered and are in contact with fresh water or seawater, October 2007.

[12] EN 113, Wood preservatives - Method of test for determining the protective effectiveness against wood destroying basidiomycetes Determination of the toxic values, 1996.

[13] Hagerman, A.E., The Tannin Handbook, www.users.muohio.edu/hagermae

[14] FAO Report, Joint meeting of the FAO panel of experts on pesticide residues in food and the environment and the WHO expert group on pesticide residues, Rome, 1994.

[15] Rowell, R. M., Handbook of wood chemistry and wood composites, Taylor \& Francis Group, 2005.

[16] Jiang, X., Fixation chemistry of amine-cooper preservatives, $\mathrm{PhD}$ Thesis, Univ. British Columbia, 2000.

[17] Evans, P.D., Schmalzl, K.J., Forsyth, C.M., Fallon, G.D., Schmid, S., Bendixen, B. and Heimdal, S., Formation and Structure of Metal Azole Complexes, J. Wood Chem. \& Techn., 27, 2008.

[18] Obanda, D.N., Shupe, T.F. and Barnes, H.M., Reducing leaching of boronbased wood preservatives, Bioresour. Technol., 99, pp. 7312-7322, 2008.

[19] Esser, P.M., van der Sloot, H.A. and Suitela, W.L.D., Harmonization of leaching tests: Leaching behaviour of wood, Heron, 46, pp. 239-252, 2006. 